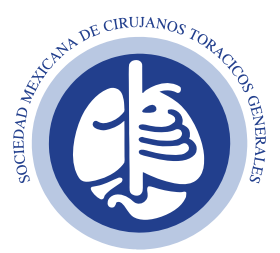

Vol. 1, Núm. 2

Mayo-Agosto 2020

pp 41-50

\title{
Recomendaciones y algoritmos de atención de pacientes con patología quirúrgica torácica en tiempos de COVID-19
}

\author{
Recommendations and care algorithms for patients with \\ thoracic surgical pathology in times of COVID-19
}

\author{
Miguel Martínez-Arias, ${ }^{*}$ Ulises Loyola-García, ${ }^{\ddagger}$ \\ Armando Otero-Pérez, ${ }^{\S}$ Manuel Escobedo-Sánchez ${ }^{\S}$
}

Palabras clave:

Algoritmo de manejo,

COVID-19, cirugía de tórax.

Keywords:

Management algorithm, COVID-19, thoracic surgery.

\footnotetext{
* Jefatura de Cirugía de Tórax y Neumología.

* Subdirección Médica.

$\S$ Médico Residente de

Cirugía Torácica General.
}

Centro Médico ISSEMyM.

Recibido: 13/10/2020

Aceptado: 13/11/2020

Correspondencia: Dr. Miguel Martínez-Arias E-mail: drmartzari@hotmail.com

\section{RESUMEN}

Debido a la actual pandemia de enfermedad por coronavirus 2019 (COVID-19), causada por el virus SARSCoV-2, es necesario efectuar modificaciones a los procesos para llevar a cabo procedimientos quirúrgicos de manera segura y con la finalidad de disminuir la exposición. Es inminente que pacientes con confirmación o sospecha de la enfermedad requerirán algún tipo de tratamiento quirúrgico, por lo que se deben tomar las medidas adecuadas para disminuir al máximo la posibilidad de contagio al personal hospitalario que participe y, así mismo, evitar complicaciones en el paciente por la toma de decisiones incorrectas. Sirvan estas recomendaciones para la aplicación de medidas de seguridad y recomendación en los procesos al realizar procedimientos quirúrgicos en pacientes confirmados o sospechosos de enfermedad por COVID-19. Partiendo desde la base que toda intervención propuesta para el paciente debe contar como máxima en el impacto directo del tratamiento y supervivencia, siendo esta intervención urgente o indispensable para su beneficio (electiva no aplazable). Deberán individualizarse en todo momento las indicaciones precisas del procedimiento, apoyado de la certeza diagnóstica tomando en cuenta la posibilidad de un tratamiento conservador como forma segura de opción terapéutica.

\section{ABSTRACT}

Due to the current 2019 coronavirus disease pandemic (COVID-19) caused by the SARS-CoV-2 virus, process modifications are needed to perform surgical procedures safely and to decrease exposure. It is imminent that patients with confirmed or suspected disease will require some type of surgical treatment so they should take appropriate measures to minimize the possibility of contagion to hospital staff involved and also avoid complications in the patient by making wrong decisions. These recommendations serve for the application of safety measures and process recommendations when performing surgical procedures on patients confirmed or suspected of having COVID-19 disease. Starting from the premise that any intervention proposed for the patient should count as a maximum in the direct impact of the treatment and survival, being this intervention urgent or indispensable for his benefit (elective not postponable). The precise indications of the procedure must be individualized at all times, supported by diagnostic certainty, taking into account the possibility of conservative treatment as a safe form of therapeutic option.
Citar como: Martínez-Arias M, Loyola-García U, Otero-Pérez A, Escobedo-Sánchez M. Recomendaciones y algoritmos de atención de pacientes con patología quirúrgica torácica en tiempos de COVID-19. Rev Mex Cir Torac Gen. 2020; 1(2): 41-50. https://dx.doi.org/10.35366/101149 


\section{INTRODUCCIÓN}

La estimación reportada de contagio al personal hospitalario es variable desde 10 a 3.8\%, México cuenta con el $17 \%$ del total de casos, ${ }^{1,2}$ es por tal motivo que el objetivo de este trabajo es establecer recomendaciones para salvaguardar la integridad del personal que se encuentra a cargo de la atención quirúrgica del paciente, teniendo en cuenta que procedimientos como intubación orotraqueal, broncoscopias, aspiración directa, nebulizaciones, ventilación manual previa a la intubación, cambios de posición del paciente con desconexión del ventilador o realización de traqueostomía son de máxima exposición y deben ser realizados por el personal más capacitado.

A continuación, se mencionan las recomendaciones extraídas de la mejores prácticas mundiales a través de la revisión de la literatura por medio de PubMed, mediante consulta de páginas web oficiales de la Organización Mundial de la Salud (OMS), los Center for Disease Control and Prevention (CDC), European Center for Disease Prevention and Control (ECDC), la Society for Healthcare Epidemiology of America y aportaciones valiosas de centros hospitalarios de Latinoamérica. Cabe mencionar que estas medidas pueden ser modificadas bajo circunstancias especiales de cada región y por variables de comportamiento dentro de la pandemia, así como resultados a posteriori.

Es de extrema importancia considerar que todo paciente sin prueba que será intervenido quirúrgicamente "es sospechoso de COVID-19 hasta no demostrar lo contrario" durante el tiempo de pandemia activa. Se tiene reporte de que en más de $50 \%$ de los casos de contagio hospitalario, el personal médico se encontraba asintomático, por lo que se deben tomar todas las medidas necesarias para reducir el contagio. 3,4

Sirvan estas recomendaciones como medidas de seguridad en los procesos, al realizar procedimientos quirúrgicos en pacientes confirmados o sospechosos de enfermedad por COVID-19.

Éstas tienen el objetivo de otorgar las herramientas necesarias para el cuidado de todo el personal hospitalario involucrado en el tratamiento médico-quirúrgico con patología torácica y que su resolución sea por vía quirúrgica.

\section{PRIORIZACIÓN DE PROCEDIMIENTOS}

Al realizar una revisión en la literatura actual, encontramos que las indicaciones quirúrgicas y los procedimientos en Cirugía Torácica (que resultan aplicables para cada rama quirúrgica) se pueden dividir en dos grupos.

Urgencia quirúrgica. Es toda condición patológica primaria o secundaria a un padecimiento de base que, en caso de no resolverse de la forma más pronta y oportuna, afectará directamente la vida y/o función de algún órgano o sistema del paciente. (P. ej. trauma penetrante, hemotórax en evolución, fuga aérea central etcétera) (Anexo 1).

Cirugía electiva no aplazable. Es todo procedimiento que, en caso de no realizarse antes dentro de los siguientes tres meses, puede influir directamente en el estado y pronóstico a corto plazo del paciente. (p. ej. traqueostomía, fijación costal en pacientes dependientes de ventilación mecánica, etcétera) (Anexo 1).

El padecimiento oncológico merece una mención especial, ya que puede cursar con complicaciones que representen una urgencia quirúrgica, así como también puede haber la necesidad de realizar procedimientos electivos no aplazables, por lo que en este caso se deberá individualizar la patología y buscar su resolución, siempre ponderando las condiciones generales del paciente, el pronóstico y la valoración del riesgobeneficio del procedimiento planeado.

Debemos considerar que, a partir de esta pandemia, 5,6 el protocolo de atención quirúrgica deberá ser modificado de forma permanente, ya que hasta el momento no se ha encontrado un tratamiento específico para esta enfermedad, así como alguna medida de control en los casos de contagio por pacientes asintomáticos, por lo que bajo nuestra perspectiva, el mejor puente para la reintegración de los servicios quirúrgicos una vez concluida la etapa activa de la pandemia, será aumentando la cantidad de procedimientos electivos no aplazables para otorgar una mayor cobertura cumpliendo con el protocolo de atención y las medidas recomendadas (Anexo 1). ${ }^{6}$

\section{RECOMENDACIONES GENERALES}

Es ideal que el personal de salud que estará involucrado en el procedimiento quirúrgico y manejo perioperatorio cuenten con las siguientes capacitaciones y conocimientos básicos: ${ }^{7,8}$ 
- Técnica de lavado de manos.

- Adecuada colocación y retiro del equipo de protección personal (EPP).

- Protocolos institucionales para el manejo y movilización del paciente.

- Idealmente contar con la mayor experiencia posible en torno al procedimiento a realizar, con la finalidad de recortar tiempos quirúrgicos. ${ }^{9-11}$

Una vez que se haya tomado la decisión de llevar al paciente a quirófano, y en caso de contar con el recurso disponible, se deben establecer las siguientes medidas generales:

- Prueba de COVID-19

- Reacción en cadena a la Polimerasa (PCR).

- Búsqueda intencionada de proceso neumónico mediante radiografía ( $\mathrm{Rx}$ ) o tomografía computarizada (TC) de tórax.

- Si el paciente no está en riesgo vital o de secuela funcional, se recomienda realizar protocolo de estudio de pacientes programados (Figura 1).

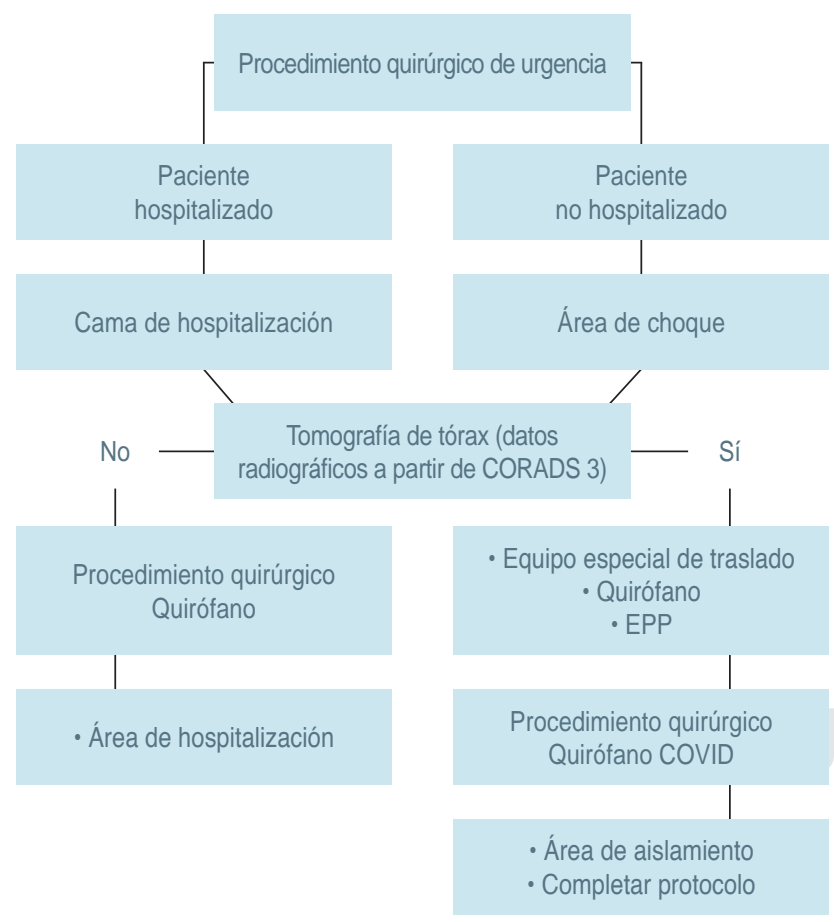

Figura 1: Algoritmo de manejo en pacientes con procedimiento quirúrgico de urgencia.

$\mathrm{EPP}=$ equipo de protección personal.
- Considerar la alternativa terapéutica que implique menor tiempo de hospitalización dependiendo del diagnóstico (drenaje, cirugía, otro).

- Preferir cirugía de control de daños y derivativa, por encima de cirugía reparadora o reconstructiva. (ejemplo: estoma $>$ anastomosis).

- Presencia en el quirófano únicamente del personal estrictamente indispensable.

- Asegurar que todo el personal que estará implicado en el procedimiento quirúrgico contará con el equipo de protección personal necesario.

- Asegurar que el paciente podrá egresar a un área aislada posterior al procedimiento, o en su defecto, a un pabellón exclusivo para pacientes COVID-19 positivos, en caso de confirmación de COVID-19 o alta sospecha del mismo.

- Evitar en lo posible la instalación de drenajes pleurales en pacientes con derrame pleural o neumotórax de baja cuantía y oligosintomáticos.

\section{TRASLADO DE PACIENTE}

Debe ser un traslado ágil, rápido y sin interrupciones. Se recomienda predefinir una vía diferente entre pacientes COVID-19 positivos y los que no lo son. ${ }^{12}$

El paciente no debe detenerse en áreas de recuperación, la fase de recuperación posterior a la cirugía debe realizarse en su área COVID, Unidad de Cuidados Intensivos o Unidades de Cuidados Intermedios.

Si se cuenta con el recurso se deberá usar cápsula aislante con camilla (traslado CV 1), la cual debe ingresar hasta sala de quirófano y sanitizar inmediatamente después de su uso.

Se recomienda utilizar algún tipo de código que indique el inicio de traslado, por ejemplo, código CV (bocinar) desde el inicio del traslado hasta su llegada a la sala de quirófano y viceversa, deberá estar marcada la ruta con señales para permitir que el resto de personal se aparte de la misma al momento de dar aviso del traslado.

Seguir la ruta unidireccional establecida de acuerdo a organización interna para traslado de pacientes COVID $(+)$ a sala de hospital adaptada a su condición respiratoria.

El personal involucrado en el transporte del paciente debe usar equipo de protección personal.

En la medida de lo posible, con respecto a las capacidades organizacionales en una unidad es- 


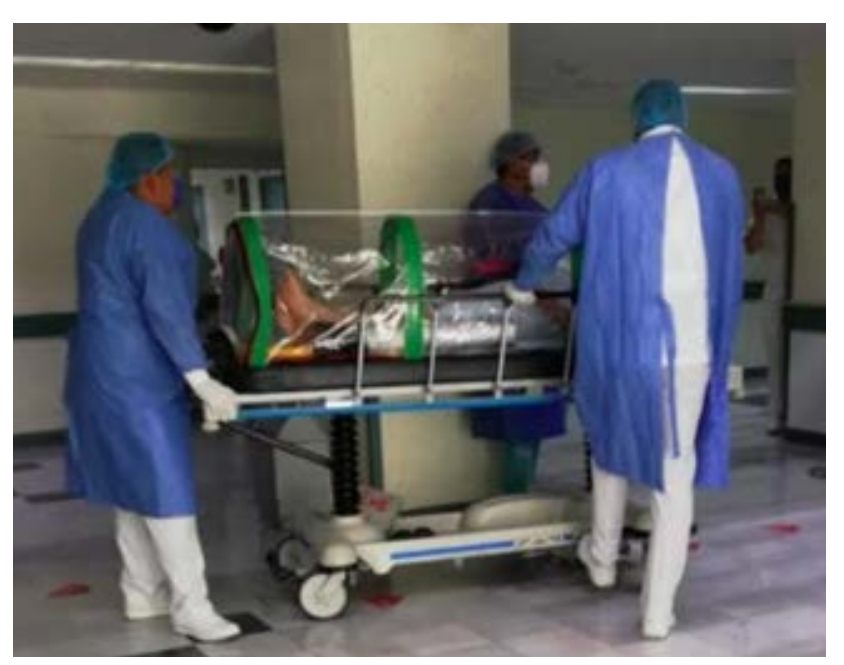

Figura 2: Traslado COVID.

pecífica, antes de transportar al paciente por las personas designadas, éstas deberán verificar que la ruta se encuentre libre de congestión y de transeúntes y notificar al médico que ordena o supervisa directamente el transporte sobre su protección. Estas personas deberán usar al menos máscaras quirúrgicas y no estar en el camino del paciente transportado (Figura 2).

Todos los empleados involucrados en el transporte deben usar mascarilla tipo N95//FFP3.

Si el paciente no está intubado, debe usar una mascarilla quirúrgica, bien ajustada a la cara, para que cubra boca y la nariz y deberá ser trasladado en la cápsula mencionada anteriormente.

Use un filtro HEPA conectado al tubo endotraqueal si se requiere respiración mecánica con una máscara de válvula de bolsa.

Durante el transporte, el uso de sistemas abiertos de oxigenoterapia se minimizará, reduciendo así el riesgo de formación de aerosoles.

Para un paciente que está siendo transportado con respiración mecánica, el filtro HEPA se colocará en el tubo de salida de aire.

Antes del transporte, prevenir el riesgo de desconexión de los componentes del sistema de flujo de aire, revisando las conexiones y su adecuado funcionamiento, además de realizar las maniobras necesarias que adicionen seguridad contra la desconexión accidental de los componentes del sistema, por ejemplo, considerar la unión con tela adhesiva.

\section{PROCEDIMIENTO QUIRÚRGICO DE URGENCIA EN PACIENTE HOSPITALIZADO Y NO HOSPITALIZADO}

Es ideal que el personal de salud que estará involucrado en el procedimiento quirúrgico y manejo perioperatorio cuenten con las siguientes capacitaciones y conocimientos básicos (Figura 3): ${ }^{13-15}$

- Técnica de lavado de manos.

- Adecuada colocación y retiro del equipo de protección personal (EPP).

- Protocolos institucionales para el manejo y movilización del paciente.

- Realizar bajo recomendaciones descritas el traslado por ruta crítica determinada previamente.

- Idealmente contar con la mayor experiencia posible en torno al procedimiento a realizar, con la finalidad de recortar tiempos quirúrgicos.

- Asumir que el paciente es PORTADOR de la enfermedad, con el aumento inherente de riesgo para el personal de quirófano. "Todo paciente es sospechoso de COVID-19 hasta no demostrar lo contrario".

- En caso de procedimiento quirúrgico abdominal, preferir cirugía de control de daños y derivativa, por encima de cirugía reparadora o reconstructiva (ejemplo: estoma $>$ anastomosis).

- Presencia en el quirófano únicamente del personal estrictamente indispensable.

- Asegurar que todo el personal que estará implicado en el procedimiento quirúrgico contará con el equipo de protección personal necesario.

- El paciente deberá egresar a un área aislada posterior al procedimiento y completar el estudio de caso para COVID-19 mediante la toma de prueba por PCR.

\section{PROCEDIMIENTO QUIRÚRGICO \\ ELECTIVO NO APLAZABLE EN \\ PACIENTES NO HOSPITALIZADOS}

Todo procedimiento programado (ambulatorio o con internamiento) se debe protocolizar con anticipación; durante este período, es necesario que se lleven a cabo las siguientes actividades, con la cronología descrita, para asegurar su efectividad (Figura 4). ${ }^{13-15}$

El paciente o familiar (idealmente uno solo) deberá acudir al hospital para programar el procedimiento, en 
caso de contar con estudios previos de imagen mayores a cinco días se deberá realizar la solicitud de tomografía computarizada de tórax.

En caso de no contar con estudio de imagen, se solicitará tomografía computarizada de tórax y en todos los casos se deberá solicitar prueba de PCR para SARS-CoV-2.

Se incluye en la solicitud la toma de muestras de laboratorio complementarias de rutina específicas para cada procedimiento en particular, así como estudios necesarios para realizar valoraciones preoperatorias.

Se debe realizar formulario en búsqueda de casos sospechosos.

El paciente deberá acudir a la realización de tomografía computarizada de tórax y PCR COVID.

Se envía al paciente a casa a aislamiento únicamente para salir el día de la cirugía programada.

Se presentará el caso a los encargados del protocolo hospitalario COVID-19 para la revisión del resultado del estudio por PCR, TC de tórax y cuestionario respiratorio.
A partir de los estudios realizados se realizarán las valoraciones preparatorias pertinentes de cada caso en particular y con las especialidades necesarias (Tabla 1).

Se realizará cirugía con prueba negativa 48 horas previas (Figura 3).

\section{PROCEDIMIENTO QUIRÚRGICO ELECTIVO NO APLAZABLE EN PACIENTES HOSPITALIZADOS}

Todo procedimiento programado en pacientes hospitalizados se debe protocolizar, es necesario que se lleven a cabo las siguientes actividades, con la cronología descrita, para asegurar su efectividad. En el caso de pacientes hospitalizados, se agregará la posibilidad de egreso a domicilio y hospitalizarse nuevamente para intervención quirúrgica. ${ }^{13-15}$

Se realiza tomografía computarizada de tórax, prueba PCR para SARS-CoV-2.

Se aplica cuestionario de paciente respiratorio sospechoso.

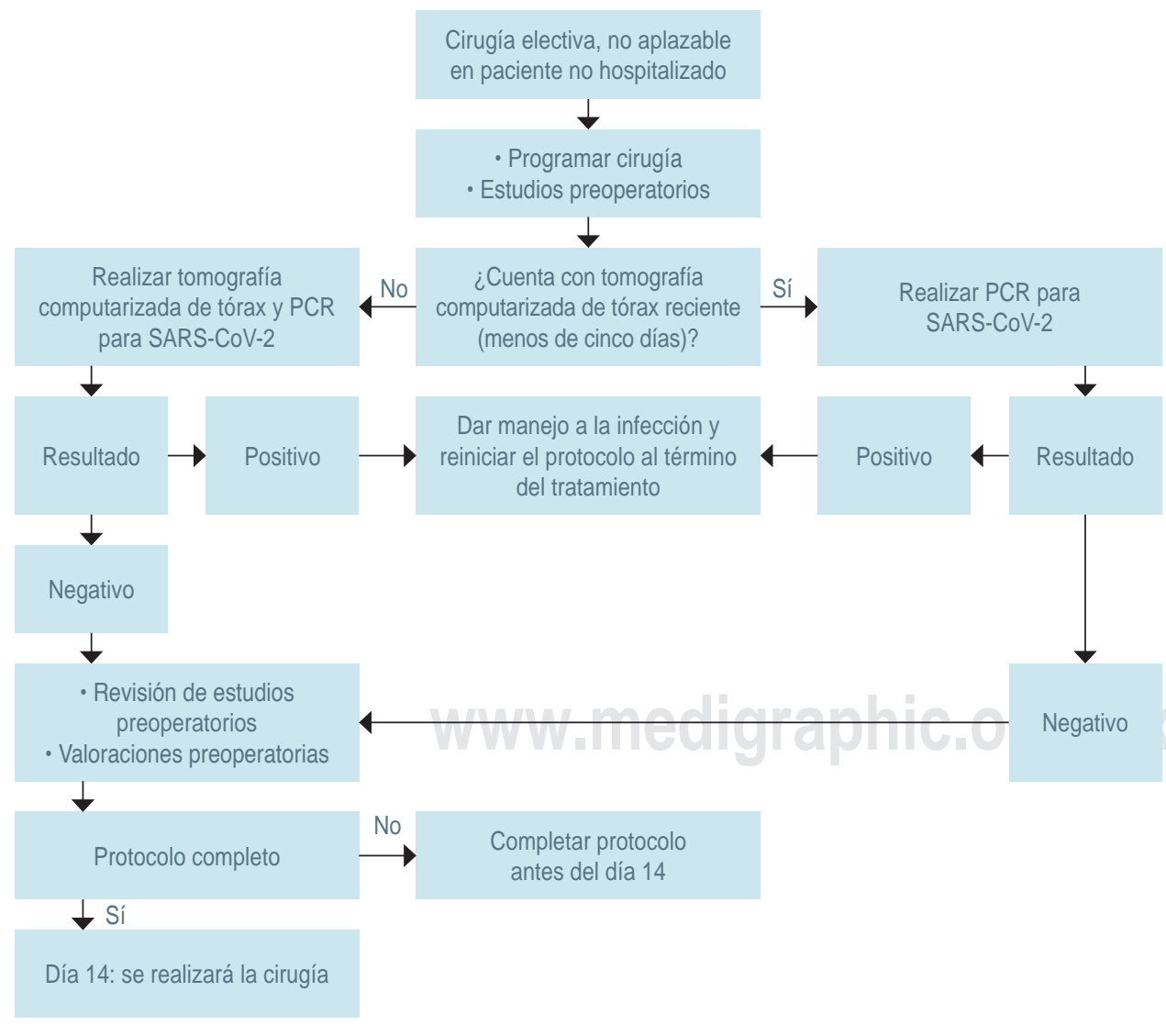

Figura 3:

Algoritmo de manejo en pacientes candidatos a cirugía electiva no aplazable en paciente no hospitalizado.

PCR = reacción en cadena a la polimerasa. 
Tabla 1: Recomendaciones para solicitud de estudio en valoración cardiovascular.

$\begin{array}{lll}\text { Entidad diagnóstica } & \text { Estudio } & \text { Tiempo de vigencia } \\ \text { Hipertensión arterial sistémica } & \text { Electrocardiograma de } 12 \text { derivaciones } & \text { Menor a tres meses (idealmente }<3 \text { días) } \\ \text { Hipertensión arterial pulmonar moderada a severa } & \text { Electrocardiograma de } 12 \text { derivaciones } & \text { Menor a tres meses (idealmente }<3 \text { días) } \\ & \text { Ecocardiograma transtorácico } & \text { Menor a un año } \\ \text { Cardiopatía estructural (cardiomiopatía isquémica, } & \text { Electrocardiograma de } 12 \text { derivaciones } & \text { Menor a tres días } \\ \text { alteración valvular, congénita, entre otras) } & \text { Ecocardiograma transtorácico } & \text { Menor a un año }\end{array}$

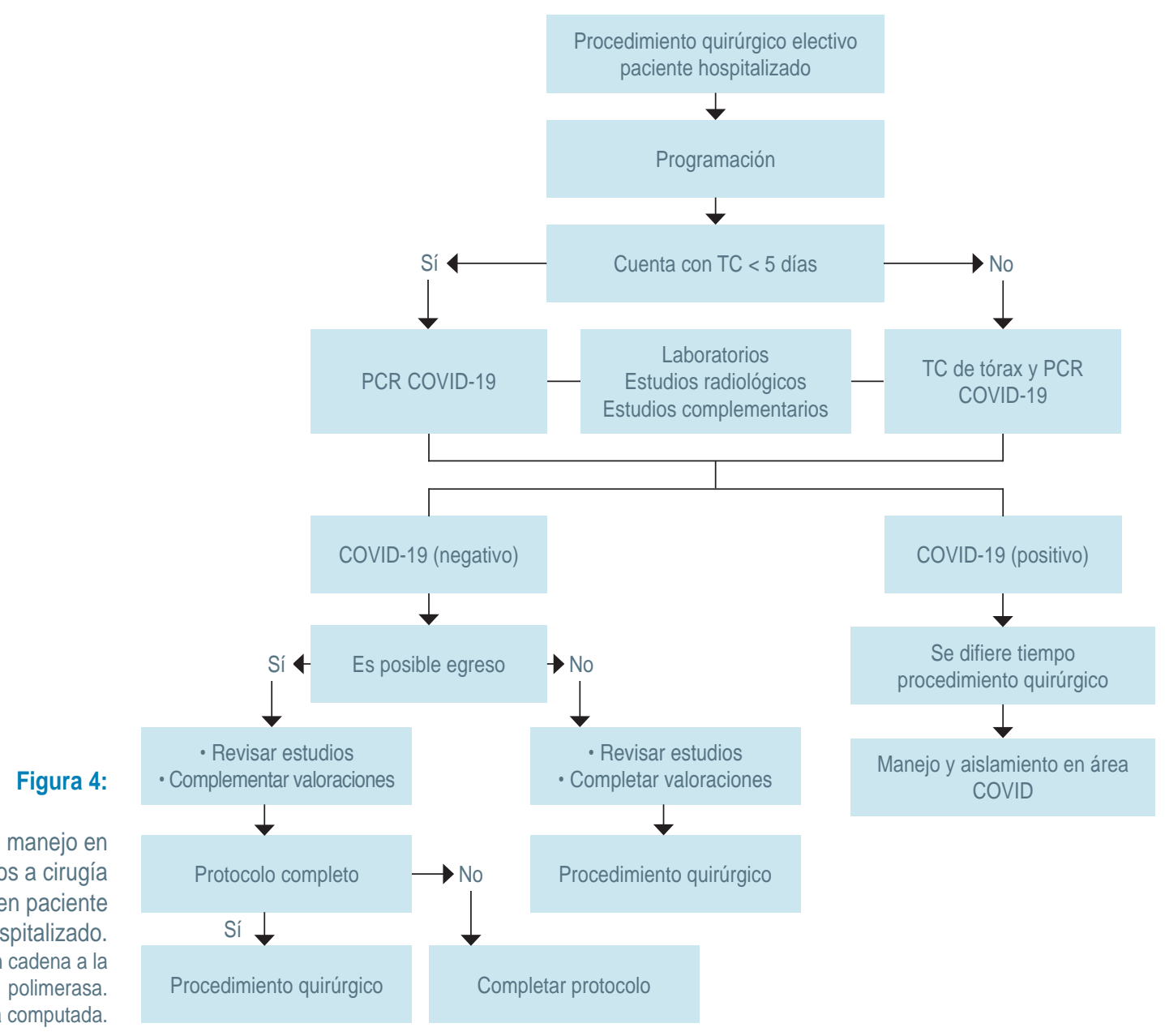

Se realiza toma de muestra para análisis de laboratorio y estudios complementarios necesarios para valoraciones preparatorias.

Si la prueba es negativa, se programa al paciente dentro de las siguientes 48 horas.

Si la prueba es positiva, se procederá al aislamiento del paciente y el procedimiento quirúrgico se diferirá.
Se presentará el caso a los encargados del protocolo hospitalario COVID-19 para la revisión del resultado del estudio por PCR, TC de tórax y cuestionario respiratorio.

A partir de los estudios realizados se realizarán las valoraciones preparatorias pertinentes de cada caso en particular y con las especialidades necesarias. 
Se realizará cirugía.

De la cirugía: se recomienda revisar cada técnica quirúrgica previo a realizar la misma en el sentido de minimizar maniobras, disminuir el tiempo quirúrgico y la posibilidad de aerolización durante el procedimiento (Figura 4).

El equipo electromecánico debe usarse con protección adecuada y sanitización previa y posterior.

No recomendamos realizar abordajes con paciente no intubado; es recomendable control de la vía aérea en todo momento.

En caso de realizar algún procedimiento en la cavidad abdominal, se recomienda utilizar neumoperitoneo a bajas presiones. La cirugía de mínima invasión, sobre todo en aquellos pacientes en los que hay necesidad de resecar alguna víscera, está recomendada, debido a que implica tener una barrera extra entre el cirujano y el tejido, también permite manipular el tejido solo con instrumentos y el medio se puede mantener con mayor control, como se indica en los siguientes párrafos.

Sellar todos los trócares, excepto los que se usan para insuflar y evacuar gas.

Usar evacuación de humo activa, es decir, mantener un aspirador disponible para esta maniobra.

Al término de la cirugía, evacuar el neumoperitoneo a través de un filtro (HEPA) de $0.1 \mu \mathrm{m}$.

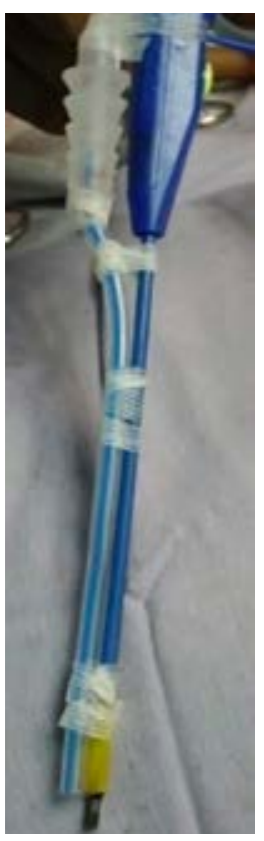

Figura 5:

Sistema de aspiración colocado en electrocauterio.

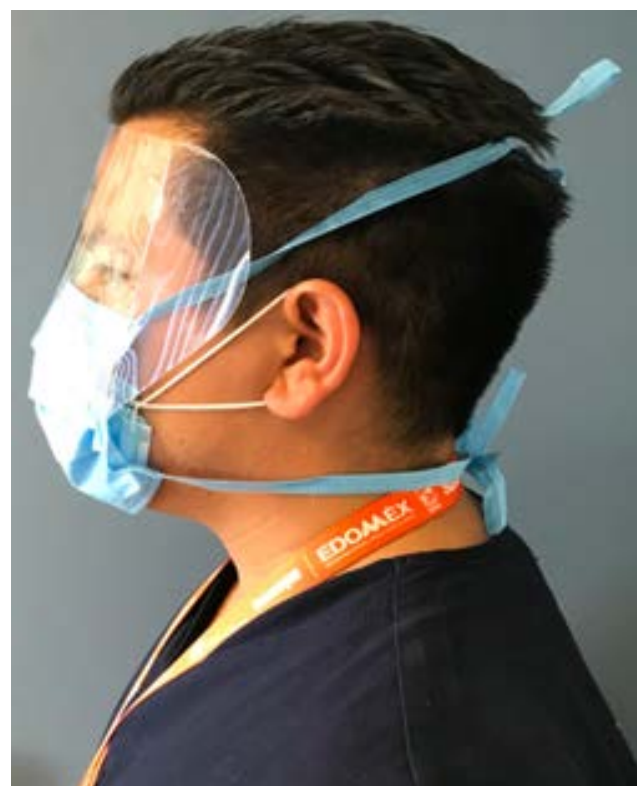

Figura 6: Movilidad y uso de cubrebocas con careta.

Manipular tejidos sólo con instrumental, nunca con las manos.

Evitar al máximo instrumentos punzocortantes.

Priorizar suturas mecánicas.

En cirugía abierta, usar dos sistemas de aspiración: uno para fluidos y uno más para aspirar posibles aerosoles en caso de usar electrocauterio o bisturí ultrasónico (estos últimos deben ser usados sólo en caso estrictamente necesario) (Figura 5). No se recomienda la utilización de aspiradores con caucho o de calibre mayor a 16FR para la succión y electrocauterio, porque disminuye el campo de visión. ${ }^{16}$

En cirugía de tórax se recomienda anestesia general, con sedación profunda y relajación para evitar reflejo de tos y poder colapsar el pulmón con el que se trabaja para evitar salpicaduras (esta recomendación aplica para el resto de las cirugías, incluidas las no torácicas).

Usar filtros HEPA para los drenajes pleurales y mantenerlos conectados a la succión.

Se recomienda el uso de drenajes cerrados con reservorios cerrados de alta capacidad.

Recomendaciones de protección personal para equipo quirúrgico: se entiende como equipo quirúrgico al conformado por el médico cirujano, ayudante, enfermera instrumentista y circulante, los cuales en todo momento deberán portar el equipo de protección 
personal, además de la bata quirúrgica estéril y guantes estériles. ${ }^{17-19}$

Nuestra recomendación para la protección facial es:

- Utilización de cubrepelo quirúrgico desechable.

- Gafas protectoras con sellado completo, en caso de no contar con ello, usar lentes de policarbonato.

- Cubrebocas N95.

- Recomendamos la utilización de cubrebocas con careta adicional (Figura 6) , debido a la baja operatividad de la careta protectora (reduce la movilidad de flexión del cirujano y contamina la bata), ya que no bloquea el flujo de aire de forma vertical ascendente.

\section{RETIRO DE EQUIPO DE PROTECCIÓN PERSONAL ANTES DE SALIR DE QUIRÓFANO}

Retirar los guantes quirúrgicos sin tocarlos por fuera, previa desinfección y lavado con solución alcoholada.

Lavado de guantes interiores con solución alcoholada.

Retiro de bata quirúrgica: evitar tocarla por fuera, plegarla envolviendo las mangas $y$, una vez llegado a los hombros, seguir plegando con la parte contaminada hacia dentro, desechar en contenedor exclusivo evitando generar corrientes de aire. ${ }^{20-23}$

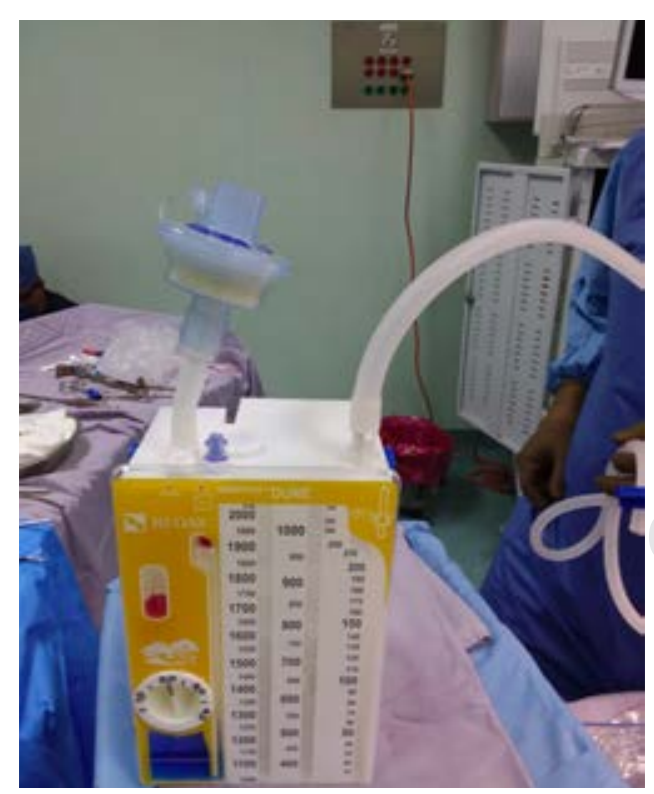

Figura 7: Filtro viral instalado en sello pleural.
Lavado de guantes interiores con solución alcoholada.

Retirada de cubrebocas con careta evitando tocar la parte externa, manipulando sólo de las cintillas y colocar en contenedor exclusivo. Si se tuvo contacto con la parte externa, se debe realizar desinfección con solución alcoholada.

Retiro de cubrepelo quirúrgico y desechar.

Retiro de cubrezapatos y desechar.

Desinfección con solución alcoholada.

Retiro de gafas de protección: se debe realizar hacia afuera, agachando la cabeza hacia el frente, para evitar contacto con los ojos y cara.

Lavado de manos con solución alcoholada.

Retiro de traje tipo Tyvek: bajar el cierre, retirar primero gorro, posteriormente, liberar ambos hombros y brazos plegando hacia afuera y evitando tocar la parte externa de la bata, y/o pijama quirúrgica, al llegar a la altura de rodillas, se puede bajar por completo. En caso de haber tocado la parte externa o ruptura accidental de los guantes, se debe realizar lavado con solución alcoholada.

Retirada de mascarilla quirúrgica: agachar la cabeza hacia adelante y sujetar las cintas desde atrás hacia adelante y hacia arriba, no se debe tocar en ningún momento la parte externa de la mascarilla, se debe desechar únicamente tomándola por las cintas.

Realizar desinfección con solución alcoholada.

Realizar retiro de cubrezapatos y bata ejerciendo presión con talones hacia el suelo del cubrezapato y bata y realizar retiro de ambos. Desechar en contenedor.

Realizar lavado de manos con solución alcoholada y retirar guantes.

Salida de quirófano a área no contaminada y realizar lavado quirúrgico de manos con agua y jabón y del paso del área designada para realizar ducha y cambio de ropa.

\section{RECOMENDACIONES PARA MANEJO DE DRENAJES}

Sondas endopleurales: se recomienda la instalación de filtro tipo HEPA conectado a la vía de escape del sello pleural, dado el riesgo de contagio por aerosoles. ${ }^{21}$

El filtro viral se debe instalar a esta conexión que tiene el sistema de drenajes a la aspiración central. Se instala entre el paciente y el sistema de drenajes, se 
satura con líquido/sangre y se ocluye. El filtro viral se puede adaptar a esta conexión mediante la utilización de un tubo orotraqueal cortado (Figura 7).

\section{CONCLUSIÓN}

La situación actual del cirujano de tórax requiere contar con todas las herramientas necesarias para la protección de su salud, estas medidas buscan disminuir el número de contagios para el personal hospitalario, ya que pueden ser aplicadas para otras especialidades médicas.

\section{REFERENCIAS}

1. Ministerio de Salud Pública, Hospital de Especialidades Eugenia Espejo; Guía de manejo y recomendaciones para traqueostomía en pacientes sospechosos y confirmados de COVID-19 versión 1.0. 2020. p. 13.

2. Zhou F, Yu T, Du R et al. Clinical course and risk factors for mortality of adult inpatients with COVID-19 in Wuhan, China: a retrospective cohort study. Lancet. 2020; 395 (10229): 1054-1062.

3. Richardson S, Hirsch JS, Narasimhan M et al. Presenting characteristics, comorbidities, and outcomes among 5700 patients hospitalized with COVID-19 in the New York City Area.JAMA. 2020; 323 (20): 2052-2059.

4. Chao TN, Braslow BM, Martin ND et al. Tracheotomy in ventilated patients with COVID-19. Ann Surg. 2020; 272 (1): e30-e32.

5. Parker NP, Schiff BA, Fritz MA et al. Tracheotomy recommendations during the COVID-19 pandemic. [Published in line, 2020] American Academy of Otolaryngology-Head and Neck Surgery.

6. Sociedad de Cirujanos de Chile, Departamento de Cirugía de Tórax, Recomendaciones para el manejo de cirugía de tórax en la pandemia de COVID-19, 2020.

7. Xiao H, Zhong Y, Zhang X et al. How to avoid nosocomial spread during tracheostomy for COVID-19 patients. Head Neck. 2020; 42 (6): 1280-1281.

8. Miles BA, Schiff B, Ganly I et al. Tracheostomy during COV-SARSCoV-2 pandemic: recommendations from the New York Head and Neck Society. Head Neck. 2020; 42 (6): 1282-1290.

9. American College of Surgeons. (2020). COVID-19?: elective case triage guidelines for surgical care. American College of Surgeons, March 24, 2020.
10. Balibrea JM, Badia JM, Rubio PI, Antona M, Álvarez PE, García BE et al. Manejo quirúrgico de pacientes con infección por COVID-19. Recomendaciones de la Asociación Española de Cirujanos. Cirugía Española. 2020; Disponible en: https://doi.org/10.1016/j. ciresp.2020.03.001.

11. Protocolo de diagnóstico y programación de cirugía electiva $A B C$ Campus Santa Fe. 2020.

12. Britsh Thoracic Society. Clinical guide for the management of critical care patients during the coronavirus pandemic. 2020; 1-7.

13. Brücher BL, Nigri G, Tinelli A, Florencio J Jr., Lapeña F, Espin E et al. COVID-19?: Pandemic surgery guidance. 2020.

14. Coccolini F. Surgery in COVID-19 patients: operational direcives. World Journal of Emergency Surgery. 2020; 15: 25.

15. Departamento de Cirugía de Tórax, Sociedad de Cirujanos de Chile. Recomendaciones para el manejo de pacientes con COVID19 en el perioperatorio. 2020.

16. Fundación DAICIM Cirugía Percutánea y COVID-19. (n.d.). 1.I50.

17. Fong ZV. Practical implications of novel coronavirus COVID-19 on Hospital Operations, Board Certification, and Medical Education in Surgery in the USA. J Gastrointest Surg. 2020; 1-5.

18. Elizalde JJ. SARS-CoV-2 and COVID-19 a pandemic review. Med Crit. 2020; 34 (1): 68-82.

19. Balibrea JM. Manejo quirúrgico de pacientes con infección por COVID-19. Recomendaciones de la asociación española de cirujanos. Cir Española Elsevier. 2020; 98 (5): 251-259.

20. Mitura K, Rogula W, Zawadzki M, Wallner G, Sobocki J. (n.d.). Guidelines for the management of surgical departments in non-uniform hospitals during the COVID-19 pandemic. Pol Przegl Chir. 2020; 92 (2): 48-59. Available in: https://doi.org/10.5604/01.3001.0014.1039.

21. Gandhi M, Yokoe DS, Havlir DV. Asymptomatic transmission, the Achilles' heel of current strategies to control COVID-19. N Engl J Med. 2020; 382: 2158-2160.

22. Liu Z, Zhang Y, Wang X, Zhang D, Diao D, Chandramohan K et al. Recommendations for surgery during the novel coronavirus (COVID-19) epidemic. Indian J Surg. 2020; 1-5. Available in: https:// doi.org/10.1007/s12262-020-02173-3.

23. Recomendaciones para el manejo de pacientes con COVID19 en el perioperatorio. Revista Chilena de Anestesia. 2020; 49 (2): 196-202. Disponible en: https://doi.org/10.25237/revchilanestv49n02.03.

Conflicto de intereses: Ninguno. 
Anexo 1: Procedimientos quirúrgicos torácicos urgentes y no aplazables.

$\begin{array}{ll}\text { Urgencias } & \text { Cirugía electiva no aplazable } \\ \text { Obstrucción de la vía aérea } & \text { Timomas } \\ \text { Hemoptisis } & \text { Cáncer pulmonar de células no pequeñas (CPCNP) resecable } \\ \text { Hemotórax } & \text { Tumores de pared torácica } \\ \text { Neumotórax } & \text { Decorticación por empiema crónico } \\ \text { Ingesta/inhalación de cuerpo extraño } & \text { Neumotórax que no responde al manejo conservador } \\ \text { Tórax inestable (sin posibilidades de extubación a corto plazo) } & \text { Fracturas costales que pueden limitar de manera importante la } \\ \text { Derrame pleural con compromiso ventilatorio } & \text { función y/o condicionan dolor importante }\end{array}$

